\title{
Description of a new species of Oligosita Haliday (Hymenoptera: Chalcidoidea: Trichogrammatidae) from India
}

\author{
Mohammad Hayat ${ }^{1}$ \& F.R. Khan ${ }^{2}$ \\ 1,2 Department of Zoology, Aligarh Muslim University, Aligarh, Uttar Pradesh 202002, India \\ Email: ${ }^{1}$ mohd_hayat@ rediffmail.com; ${ }^{2}$ insectqh11@ rediffmail.com
}

Date of online publication 26 February 2009 ISSN 0974-7907 (online) | 0974-7893 (print)

Editor: T.C. Narendran

\section{Manuscript details:}

Ms \# 01924

Received 19 January 2008

Finally accepted 25 March 2008

Citation: Hayat, M. \& F.R. Khan (2009). Description of a new species of Oligosita Haliday (Hymenoptera: Chalcidoidea: Trichogrammatidae) from India. Journal of Threatened Taxa 1(2): 117-118.

Copyright: (C) M. Hayat \& F.R. Khan 2009. Creative Commons Attribution 3.0 Unported License. JoTT allows unrestricted use of this article in any medium for non-profit purposes, reproduction and distribution by providing adequate credit to the authors and the source of publication.

Author Details: Dr. M. HAYAT, a Ph.D. and D.Sc. in Zoology from the Aligarh Muslim University. More than 40 years research experience on chalcidoid Hymenoptera, mainly Encyrtidae, Aphelinidae, Mymaridae, Trichogrammatidae and Signiphoridae. Retired in August 2006 as Professor in Zoology. Working as a Principal Investigator in an ICAR funded 'Network Project on Insect Biosystematics' since September 2005.

Dr. F.R. KHAN, Ph.D. in Zoology. Presently working as Research Associate in the 'Network Project on Insect Biosystematics' at the AMU, Department of Zoology centre. He has to his credit several papers on grasshoppers ecology, and recently on taxonomy of some chalcidoid families.

Author contributions: M. HAYAT did the main work on identifications and description of the species. F.R. KHAN collected the specimens, provided help in identification, and prepared the final manuscript on the computer.

Acknowledgements: The authors are thankful to the ICAR and Dr. V.V. Ramamurthy, Division of Entomology, IARI, New Delhi, the National Coordinator of the "Network Project on Insect Biosystematics" for financial assistance. The authors are also grateful to the authorities of the Aligarh Muslim University and the Chairman, Department of Zoology, for providing facilities.
Abstract: A new species of the trichogrammatid genus Oligosita Haliday, O. sakara, sp. nov., is described based on specimens collected in Uttar Pradesh and Orissa, India.

Keywords: Indian Trichogrammatidae, Oligosita new species.

The trichogrammatid genus Oligosita Haliday in Walker (1851) contains more than 120 species worldwide. Recently, Hayat (2008 a, b) studied the types of all but one species of Oligosita described by Mani (1939) and Yousuf \& Shafee (1984, 1988, 1992), and recorded material pertaining to six species. In all, Hayat (2008b) recognized 17 valid species from India and gave a key to these species. In this paper, a new species of the genus is described from specimens collected from Uttar Pradesh and Orissa.

\section{Oligosita sakara sp. nov.}

(Figs. 1-7)

\section{Material examined}

Holotype: Female (on slide), 1.x.2006, Tikona Mod, Bahraich, Uttar Pradesh, India, coll. F.R. Khan. Deposited in National Pusa Collection, Division of Entomology, Indian Agricultural Research Institute, New Delhi (NPCI), Registration no. 13/6/59/1.

Paratypes: 4 Females (on slides), same data as per holotype; 1 Female (on slide), 26.ix.2006, Lakhkhi Purwa, Lakhimpur, Uttar Pradesh, coll. S.M.A. Badruddin \& F.R. Khan; 2 Females (on one slide), 27.ix.2006, Imami Purwa, Lakhimpur, Uttar Pradesh, coll. S.M.A. Badruddin \& F.R. Khan. Two paratypes from Imami Purwa, deposited in NPCI, No. 13/6/59/2; rest of the paratypes in Insect Collection, Department of Zoology, Aligarh Muslim University, Aligarh

Additional specimens examined, but not designated as types: (All specimens are on cards): 2 Females, 26.xi.2007, Benipur, Bhubaneswar, Orissa; 1 Female, 29.xi.2007, Chandpur, Puri, Orissa; 4 Females, 1.xii.2007, Matiapada, Puri, Orissa; 1 Female, 4.xii.2007, Harrajpur, Khorda, Orissa; 1 Female, 11.xii.2007, Budharaja, Sambalpur, Orissa; 2 Females, 15.xii.2007, Sarbahai, Jharsuguda, Orissa (All coll. F.R. Khan).

\section{Etymology}

The specific name is an arbitrary combination of letters.

\section{Description}

Female: Length, 0.51-0.60 mm; Head, pronotum, mesopleuron, metapleuron, gasteral terga beginning posterior half of third tergite (T III) to T VII, except white apex of T VII, dark brown; two patches in about anterior two-thirds of mid lobe of mesoscutum, sides of propodeum, posterior half of T II and anterior half of T III, brown; ovipositor sheaths dark brown; rest of body pale yellow (Figs. 6, 7); antenna pale infuscate brown yellow; wings hyaline with a faint yellow tinge, with slight infuscated spots at base of parastigma and at apex of stigmal vein; veins yellow-brown; last tarsal segment of all legs brown.

Head: compared to other Indian species, flattened; dorsum about $5 \mathrm{x}$ as broad as long, with vertex at level of posterior ocelli, about $4 \mathrm{x}$ as broad as long (Fig. 2) [These dimension vary in specimens treated with $\mathrm{KOH}$ and mounted in balsam. See Fig. 1]; malar sulcus present; malar space two-fifths of eye length; head, in front view, 1.3x as broad as high in a normally preserved specimen; vertex with transversely elongate reticulations, but from sides of eyes down to near the lower margins of eyes with longitudinally elongate ridge-like reticulations (Fig. 1); ocellar triangle with apical angle strongly obtuse; setae as in Figs $1 \& 2$. Mandibles with two teeth and a truncation. Maxillary palp unsegmented. 


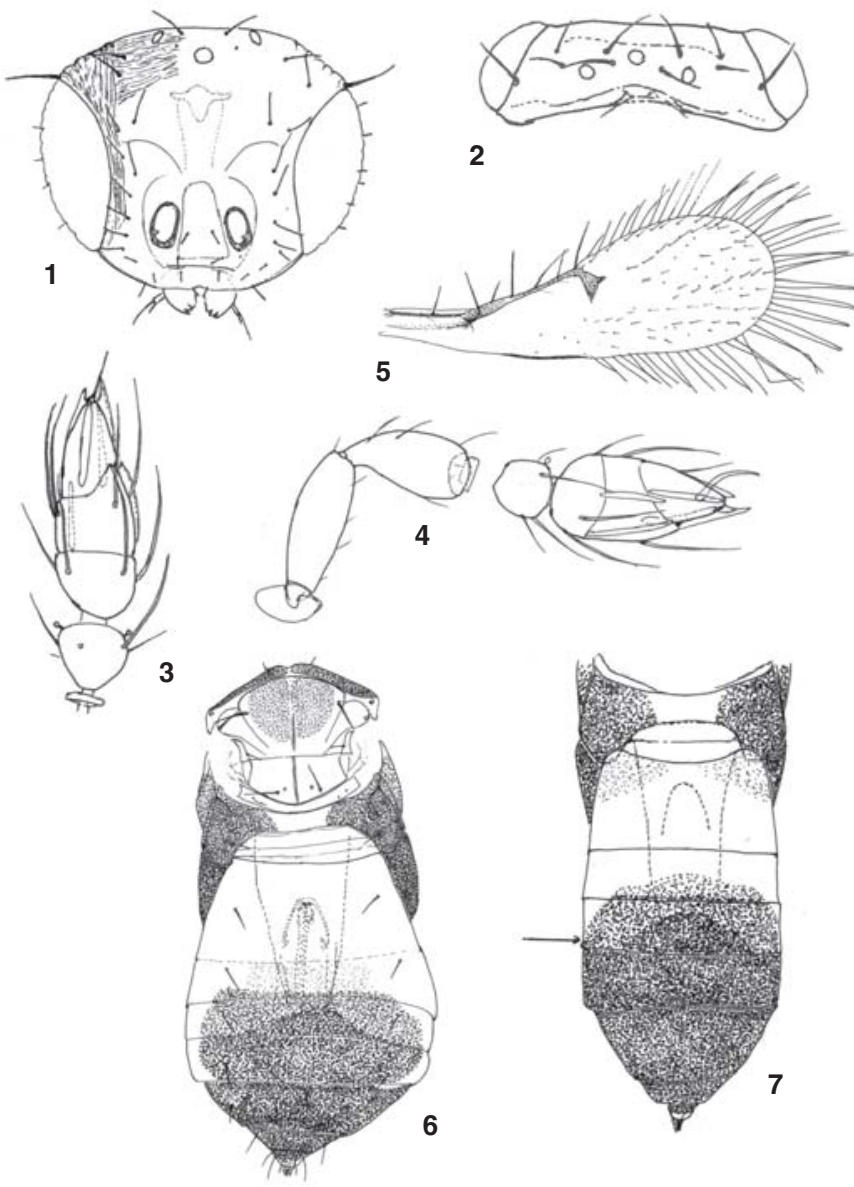

Figures 1-7. Oligosita sakara sp. nov. (Female)

1 - Head frontal view; 2 - head dorsum; 3 - flagellum;

4 - antenna, scape and pedicel from left antenna, flagellum from right antenna; 5 - fore wing; 6- thorax and gaster, gaster distended; 7 propodeum and gaster showing colour, normal. Figures 1, 3, 5 and 6 from holotype; 2, 4 and 7 from paratypes.

Antenna (Figs. 3, 4) with scape slightly longer than pedicel $(5: 4.5)$ and shorter than clava (5:6.5); funicle segment as long as broad and as long as first segment of clava; clava 2.25 to $2.75 \mathrm{x}$ as long as broad, apical segment with a hook-like bristle (Fig. 4).

Thorax: somewhat flattened; setation and dimensions as in Fig. 6. Fore wing (Fig. 5) about $3 \mathrm{x}$ as long as broad; marginal fringe $0.65 \mathrm{x}-0.70 \mathrm{x}$ of wing width. Hind wing $16.4 \mathrm{x}$ as long as broad; marginal fringe $2.8 \mathrm{x}$ as long as wing width.

Gaster: depending upon the state of preservation and if not stretched as in Fig. 6, 1.76x to $1.90 \mathrm{x}$ as long as thorax; gasteral tergites 1 and 5 ( T I, T V) long; setae on tergite as follows; T I, 1+1; T II, 1+1; T III, 1+1; T IV, 1+2+1; T V, $1+2+1$; TVI 1+2+1; T VII, 4; ovipositor as seen through the derm, appears to originate from about basal third to half of $\mathrm{T}$ $\mathrm{I}$, and very slightly exserted at apex; ovipositor varies from $1.57 \mathrm{x}$ to $1.87 \mathrm{x}$ as long as hind tibia; in holotype, $1.87 \mathrm{x}$ as long as hind tibia.

Male: Unknown.

Host: Unknown.
Comments: This new species does not agree with any of the available descriptions of the species (Nowicki 1935, 1936; Viggiani 1976, 1981; Yousuf \& Shafee 1984, 1988, 1992; Lin 1994; Hayat 2008b) of Oligosita. However, it appears related to O. aesopi Girault (1929) as it runs near that species in the key to the Australian species given by Viggiani (1976), but O. aesopi has an obscure yellow body, scape about $2 \mathrm{x}$ as long as pedicel and fore wing marginal fringe a little shorter than width of wing. This species was mentioned as 'Oligosita sp. indet. D' in the key to the Indian species of Oligosita given by Hayat (2008b).

\section{References}

Girault, A.A. (1929). North American Hymenoptera Mymaridae. Addendum. p.28. Brisbane, 8 January 1929 (privately published)

Hayat, M. (2008a). Taxonomic notes on the Indian Trichogrammatidae (Hymenoptera: Chalcidoidea) with redescriptions and records of some species. Oriental Insects 42: 1-32.

Hayat, M. (2008b). On the types of Oligosita species from India (Hymenoptera: Chalcidoidea: Trichogrammatidae), with some records. Biosystematica 2: 5-18.

Lin, N.Q. (1994). Systematic studies of Chinese Trichogrammatidae. Contributions of the Biological Control Research Institute, Fujian Agricultural University, Special Publication No. 4: 362pp [In Chinese, with English Summary].

Nowicki, S. (1935). Descriptions of new genera and species of the family Trichogrammatidae (Hym. Chalcidoidea) from the Palearctic region, with notes- I. Zeitschrift für Angewandte Entomologie 21: 566596

Nowicki, S. (1936). Descriptions of new genera and species of the family Trichogrammatidae (Hym. Chalcidoidea) from the Palearctic region, with notes- II Zeitschrift fir Angewandte Entomologie 23: 114148

Viggiani, G. (1976). Ricerche sugli Hymenoptera Chalcidoidea L. Materiali per una revisione del genere Oligosita Walk. (Trichogrammatidae) 1. Le specie australiane descritte da A. A. Girault. Bollettino del Laboratorio di Entomologia Agraria "Filippo Silvestri" di Portici 33: 188-218.

Viggiani, G. (1981). Nearctic and Neotropical species of Oligosita Walker (Hymenoptera: Trichogrammatidae). Bollettino del Laboratorio di Entomologia Agraria "Filippo Silvestri" di Portici 38: 101-118.

Walker, F. (1851.) Notes on chalcidites, and description of various new species. Annals and Magazine of Natural History, London 7: 210-216.

Yousuf, M. \& S.A. Shafee (1984). Species of Oligosita Walker (Hymenoptera: Trichogrammatidae) from India. Indian Journal of Systematic Entomology 1: 15-22.

Yousuf, M. \& S.A. Shafee (1988). Taxonomy of Indian Trichogrammatidae (Hymenoptera: Chalcidoidea). Indian Journal of Systematic Entomology 4: 55-200.

Yousuf, M. \& S.A. Shafee (1992). Two new species of Oligosita Haliday (Hymenoptera: Trichogrammatidae) from Meerut, India. Bulletin of Pure and Applied Sciences 11A: 15-16.

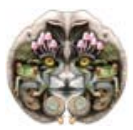

